\title{
Manufacture of silicon carbide reinforced aluminium 6061 metal matrix composites for enhanced sliding wear properties
}

\author{
Avinash Bhat and Ganesh Kakandikar \\ School of Mechanical Engineering, Dr. V. D. Karad MIT World Peace University, Pune, India
}

Received: 5 July 2019 / Accepted: 15 September 2019

\begin{abstract}
Composite materials have the capability of being customised to provide specific mechanical and tribological properties. This paper presents the manufacture of a novel composite of Al6061 with $5 \% \mathrm{SiC}(50 \mu \mathrm{m}$ size) by the stir casting method. Experimental investigations of mechanical and tribological properties of $\mathrm{SiC}$ reinforced Al6061 are discussed. Investigations with a Rockwell hardness tester revealed that this composite had enhanced hardness. Wear characteristics were investigated for Al6061 and the novel composite Al6061 + SiC with a Pin on disc tribometer for a load range of $5 \mathrm{~N}-200 \mathrm{~N}$ and RPM varying from 200 to 1500 . The effect of crucial parameters such as load and RPM on the wear of the novel composite were presented with sensitivity analysis. The results obtained are encouraging, showing the novel composite having a lower wear rate.
\end{abstract}

Keywords: Metal matrix / composite / wear / Al6061 / SiC / stir casting

\section{Introduction}

There is a constant need for improvements in material properties across a wide range of applications, such as transportation, aerospace, military engineering, etc. A specific requirement is the development of light weight high strength materials with improved mechanical properties. This can be achieved by developing a new class of materials so as to meet the challenging issues posed within engineering applications. Composites are one class of materials that can impart desired customized mechanical properties. In composites, two or more materials are combined together in order to give a unique combination of properties. Metal matrix composites (MMC) are fabricated with a matrix as a base light metal such as aluminium (Al), magnesium, or titanium and reinforced with various ceramic fibres [1-3].

Different fabrication methods are used for processing metal matrix composites such as: stir casting, infiltration, diffusion bonding, powder metallurgy, and deposition techniques. The selection of the fabrication method for making the composite has an influence on the material behaviour. The fabrication method can affect reinforcement distribution, homogeneity, clustering/agglomeration, wettability, hardness distribution, and density distribution, etc. which influence the mechanical behaviour of the material [4].

\footnotetext{
* e-mail: kakandikar@gmail.com
}

The stir casting technique is the most widely used technique for the fabrication of MMC's. In this method, the molten metal is stirred continuously with the help of a stirrer or an impeller usually made of graphite and the discontinuous reinforcement is incorporated into the matrix. An inert gas is blown into the crucible during operation in order to avoid any chemical reaction. The mixture is then poured in to the mould to obtain the desired shape [4,5]. In the preparation of metal matrix composites with the help of the stir casting method, there are various factors that need considerable attention, these include: (a) achieving a uniform distribution of the reinforcement; (b) Wettability between the main substances; (c) Porosity; and (d) chemical reactions between the ingredients. However, the above challenges could be taken care by effectively controlling the process parameters such as stirring speed, stirring time, stirrer depth, feed rate, etc. Wettability could be reduced by putting $1 \%$ Magnesium into the mould. By using inert conditions, we can reduce the possibility of chemical reaction between the constituents [5-8].

MMC's can be manufactured using wide range of reinforcing material such as silicon carbide $(\mathrm{SiC})$, aluminium oxide $\left(\mathrm{Al}_{2} \mathrm{O}_{3}\right)$, boron carbide $\left(\mathrm{B}_{4} \mathrm{C}\right)$, titanium dioxide $\left(\mathrm{TiO}_{2}\right)$, boron nitride $\left(\mathrm{B}_{4} \mathrm{~N}\right)$, etc. The reinforcing material can be of different sizes from $10 \mu \mathrm{m}$ to $100 \mu \mathrm{m}$. The impingement of the reinforcement increases the physical, tribological and mechanical properties of the base matrix $[9,10]$.

Wear is the gradual material removal from the solid surface when one material harder than the other rub against each other. Wear is not a material property but it 
Table 1. Composition of Al 6061 alloy.

\begin{tabular}{|c|c|c|c|c|c|c|c|c|c|}
\hline $\mathrm{Si}$ & $\mathrm{Fe}$ & $\mathrm{Cu}$ & Mn & $\mathrm{Mg}$ & $\mathrm{Cr}$ & $\mathrm{Zn}$ & $\mathrm{Ti}$ & Other elements & $\mathrm{Al}$ \\
\hline 0.62 & 0.45 & 0.20 & 0.18 & 1.05 & 0.09 & 0.03 & 0.07 & 0.2 & Remainder \\
\hline
\end{tabular}

depends on conditions to which the material is subjected [11]. Load, speed and distance between them are the three main wear testing parameters [12].

Literature indicates that when an $\mathrm{Al}$ matrix is reinforced with $\mathrm{SiC}$ its characteristic behaviour is that with the increase in weight percentage of $\mathrm{SiC}$, the hardness, tensile strength and density of the MMC increased while toughness decreased. The strength to weight ratio was found to be 3 times more than mild steel [13]. In the microstructural evaluation, uniform distribution of nano $\mathrm{SiC}$ is observed in the metal matrix and also the strong bonding between the constituent and matrix at the interface [14].

A clustered region was observed when $\mathrm{SiC}$ was reinforced in Al7075 alloy matrix and then it increased with the increase of reinforcement content or with the reduction of particle size. Porosity and micro hardness increased with an increase of wt.\% of SiC. Also the micro structural studies revealed a uniform distribution of particles and the micro hardness, wear resistance and the tensile strength were found higher than the base matrix. The density of the composites was also found to be increased $[15,16]$. The coefficient of friction and wear rates are reduced as compared to the base metal. However it increased with an increase in sliding speed [17]. Al 6061 reinforced with $\mathrm{SiC}$ also showed similar results as above [18]. Porosities were observed when Aluminium was reinforced with $\mathrm{SiC}$ [19]. A Design of Experiment was conducted as per the L27 orthogonal array Taguchi method using MINITAB 17 in order to determine the optimum number of experiments and optimum manufacturing conditions to fabricate Silicon Carbide and Copper reinforced Aluminium metal matrix composite [20-22].

$\mathrm{Al} 6061$ being ductile and soft in nature has very low physical and tribological (wear) properties. Hence in order to increase the wear characteristics we must incorporate some kind of hard ceramics in the Al 6061 alloy. With the addition of reinforcement, $\mathrm{SiC}$ in this case, the wear characteristics of $\mathrm{Al} 6061$ alloy was found to be enhanced. However, low research is observed in the area of variations in percentage weight of $\mathrm{SiC}$. Also wear characterization of the $\mathrm{SiC}$ reinforced $\mathrm{Al} 6061$ alloy at high load and high RPM has not been done. This paper therefore focuses mainly on finding the hardness and wear of the $\mathrm{SiC}$ reinforced alloy ( $5 \%$ by wt.) at high load and high RPM.

This paper presents a dry sliding wear test on $\mathrm{SiC}$ reinforced aluminium 6061 metal matrix composites. The results showed that with the volume percentage increase of the reinforcement, the wear was found to be decreased. Empirical relations were established using statistical regression analysis and ANOVA to estimate wear. Using this newly developed model the wear was analysed. The volume percentage of the reinforcement was more influential than other factors such as low load, low rotation speed and high counter face hardness. The failure occurred due to the abrasive wear mechanism is presented.

\section{Methodology and experimental investigations}

A new combination of $\mathrm{Al}$ and $\mathrm{SiC}$ metal matrix composite is manufactured and wear characteristics were studied as discussed in following sections.

\subsection{Material selection}

The base matrix for the present study is aluminium 6061 alloy and the reinforcement used is Silicon Carbide (5\% wt.) of size $50 \mu \mathrm{m}$ each. The chemical composition of $\mathrm{Al}$ 6061 alloy is presented in Table 1 . Magnesium $(\mathrm{Mg} 1 \%)$ and flux $(1 \%)$ was added to enhance the wettability of reinforcement with the matrix.

\subsection{Manufacturing of the composite}

Production of composite materials of standard quality is influenced by correct choice of operating parameters, such as melting temperature, mixing speed, preheating temperature of reinforcing material, and the like. The procedure applied in the preparation of the composite is as follows. About $1 \mathrm{~kg}$ of Al6061 alloy was heated to a melted state in a graphite crucible using an induction resistance furnace. The melt temperature was $750^{\circ} \mathrm{C}$. After the alloy was completely melted, a stainless steel stirrer was introduced into the molten alloy, consisting of two blades coated with Boron Nitride non-stick paste, and the mixing process began. Boron nitride non-stick coatings are used to prevent the sticking of molten metal to the inner surface of the crucible. The mixer was rotated at $500 \mathrm{rpm}$ for $30 \mathrm{~min}$. The immersion depth of the agitator is maintained at about $2 / 3$ of the depth of the molten metal. The stir casting process setup is shown in Figure 1. During mixing, a $5 \%$ by weight fraction of the pre-heated reinforcing particles $\mathrm{SiC}$ is added to the vortex formed with stirring. Before this, the reinforcing particles were preheated to $250^{\circ} \mathrm{C}$ for one hour. After adding the particles to the melt, the composite alloy is poured into a preheated $\left(300^{\circ} \mathrm{C}\right)$ mould of permanent steel and cooled to ambient temperature. The preform is then removed from the mould.

Thus the Al6061-SiC composite was obtained with a 5\% by weight fraction of reinforcing materials from which wear samples were processed.

\subsection{Preparation of test specimen}

After the manufacture of the composite the wear test specimen was made using Water Jet Machining, the specimen having dimensions $15 \mathrm{~mm} \times 15 \mathrm{~mm} \times 50 \mathrm{~mm}$. The pins for wear test were then machined to exact dimensions $10 \mathrm{~mm} \times 10 \mathrm{~mm} \times 50 \mathrm{~mm}$ by using a milling operation. 


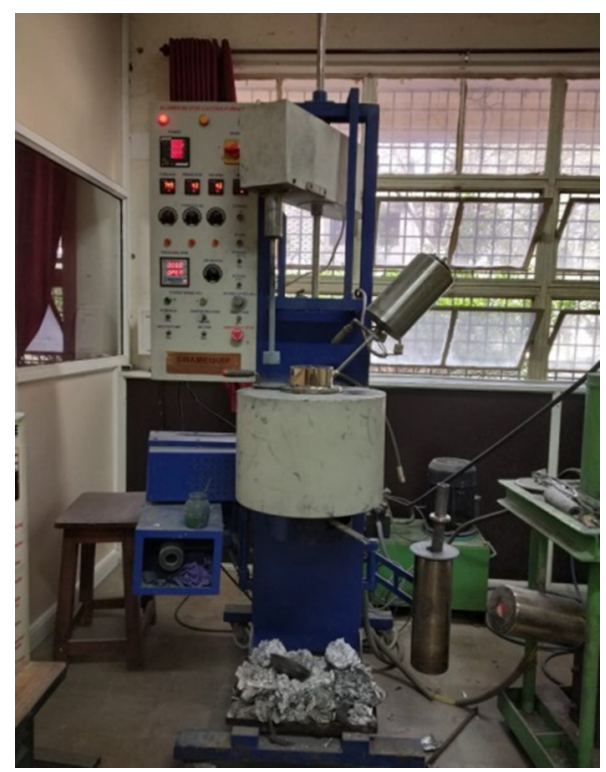

Fig. 1. Stir casting setup.

\subsection{Hardness test}

The hardness of the $\mathrm{Al} 6061$ alloy and the composite is determined using a Rockwell hardness tester. A $100 \mathrm{~kg}$ load was applied on the polished specimen for $10 \mathrm{~s}$ by a ball indentor. To avoid the effect of segregation of reinforcement in matrix, 10 readings of each sample were taken and the results are not tabulated. Using the hardness conversion table, the hardness value was then converted in to a Brinell hardness number.

\subsection{Wear test}

Dry sliding wear tests were conducted on the pin and disc setup in ambient conditions as per ASTM G99 standard. High carbon high chromium steel discs of hardness $658 \mathrm{HB}$ having diameter $165 \mathrm{~mm}$ and thickness of $8 \mathrm{~mm}$ were used. Response Surface Methodology was applied in designing nine experiments with two variables, load and number of rotations. The load ranged from $5 \mathrm{~N}$ to $200 \mathrm{~N}$ and the rpm ranged from 200 to $1500 \mathrm{rpm}$. The surface of the disc and samples were cleaned with an acetone solution before the wear test.

The specific wear rate can be calculated as shown below:

- wear amount = mass loss $(\mathrm{kg})$ or linear dimensional change $(\mathrm{m})$ or volume loss $\left(\mathrm{m}^{3}\right)$.

- wear resistance $=1 /$ (wear amount $)\left(\mathrm{m}^{-1}, \mathrm{~m}^{-3}, \mathrm{~kg}^{-1}\right)$.

- wear rate $=($ wear amount $) /($ sliding distance or time $)$ $\left(\mathrm{m} / \mathrm{m}, \mathrm{m}^{3} / \mathrm{m}, \mathrm{kg} / \mathrm{m}, \mathrm{m} / \mathrm{s}, \mathrm{m}^{3} / \mathrm{s}, \mathrm{kg} / \mathrm{s}\right)$.

- wear coefficient, or specific wear rate (also sometimes called wear factor $)=($ wear rate $) /($ normal force $)$ $\left(\mathrm{m}^{3} / \mathrm{N}^{-1} \mathrm{~m}^{-1}\right)$

\section{Results and discussions}

The mechanical properties of the proposed composite strongly depend on the weight fraction of reinforcing

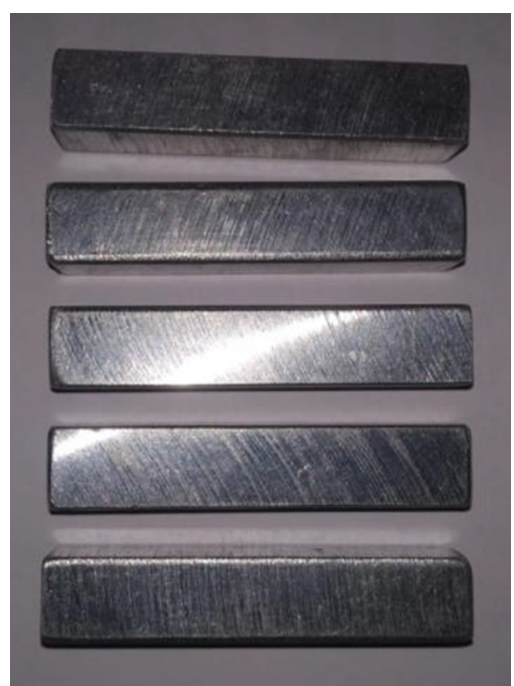

Fig. 2. Pins of Al6061.

Table 2. Design of experiment for wear test.

\begin{tabular}{lll}
\hline Experiment No. & Load $(\mathrm{N})$ & RPM \\
\hline 01 & 46 & 346 \\
02 & 173 & 346 \\
03 & 46 & 1053 \\
04 & 173 & 1053 \\
05 & 20 & 700 \\
06 & 200 & 700 \\
07 & 110 & 200 \\
08 & 110 & 1200 \\
09 & 110 & 700 \\
\hline
\end{tabular}

particles on the alloy substrate. Reinforcement enhances the material properties of composite. It has been found that the hardness of SiC-reinforced MMC is better than that of $\mathrm{Al} 6061$ alloy as seen in Figure 2. The increase in hardness from $81 \mathrm{HB}$ of $\mathrm{Al} 6061$ to $135 \mathrm{HB}$ of the newly developed composite of $\mathrm{Al} 6061$ and $\mathrm{SiC}$ is encouraging.

In the case of aluminium alloy 6061, adhesive wear was observed, because it was malleable, while in case of the MMC having a content of silicon carbide abrasive wear was observed. The wear test results for the nine experiments conducted on Al6061 alloy and $\mathrm{Al} 6061+\mathrm{SiC}$ is shown in Table 3.

It is evident from the results that for all experiments the specific wear rate for the newly developed alloy of Al6061 $+5 \% \mathrm{SiC}$ is far lower than that of Al6061, certifying that the newly developed composite has better wear characteristics. The same has been represented in chart comparing every experiment Figure 5.

Load and RPM are the two most important factors influencing wear. Experiments were conducted to carry out sensitivity analysis of load, wear and RPM. Experiments with constant RPM of 200, 700 and 1200 for Al6061 
Table 3. Wear results of nine experiments.

\begin{tabular}{|c|c|c|}
\hline Experiment No. & $\begin{array}{l}\text { Specific wear rate } \\
\text { for } \mathrm{Al} 6061 \\
+5 \% \mathrm{SiC}[\mu \mathrm{m}]\end{array}$ & $\begin{array}{l}\text { Specific wear rate } \\
\text { for Al6061 }[\mu \mathrm{m}]\end{array}$ \\
\hline 01 & 329.79 & 567.75 \\
\hline 02 & 849.68 & 1199.28 \\
\hline 03 & 668.22 & 1559.99 \\
\hline 04 & 1729.49 & 2618.17 \\
\hline 05 & 236.26 & 719.4 \\
\hline 06 & 1497.15 & 2047.9 \\
\hline 07 & 461.27 & 539.79 \\
\hline 08 & 1289.7 & 2340.06 \\
\hline 09 & 978.83 & 1681.9 \\
\hline
\end{tabular}

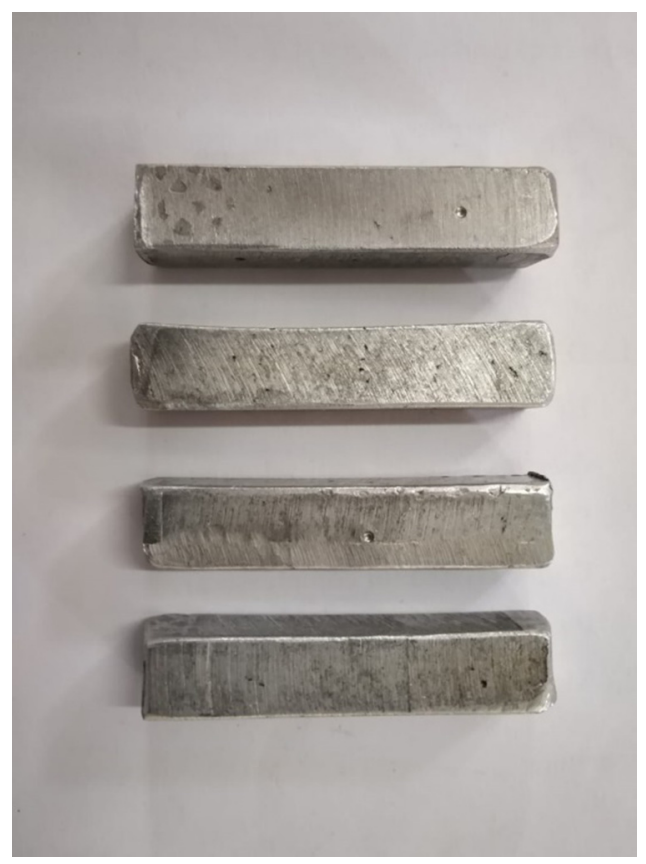

Fig. 3. Al6061 $+\mathrm{SiC}$ pins.

revealed that specific wear rate increases with an increase with load. For 200 RPM it ranges between $316 \mu \mathrm{m}$ and $948 \mu \mathrm{m}$, for $700 \mathrm{RPM}$ it ranges between $739 \mu \mathrm{m}$ and $2219 \mu \mathrm{m}$ and for $1200 \mathrm{RPM}$ it ranges between $1065 \mu \mathrm{m}$ and $3199 \mu \mathrm{m}$ with load range of $20 \mathrm{~N}$ to $200 \mathrm{~N}$. At higher RPM, the specific wear rate also increases, as presented in Figure 6 .

At constant load the wear rate increases as the RPM increases while with the increase in load an increase in wear rate was observed for the same RPM as seen from Figure 7.

For $20 \mathrm{~N}$ load the specific wear rate ranges between $316 \mu \mathrm{m}$ and $1065 \mu \mathrm{m}$, for $110 \mathrm{~N}$ it ranges between $713 \mu \mathrm{m}$ and $2405 \mu \mathrm{m}$ and for $200 \mathrm{~N}$ it ranges between $948 \mu \mathrm{m}$ and $3199 \mu \mathrm{m}$. It is also evident that at higher loads, the specific wear rate for Al6061 increases rapidly with an increase in RPM as compared to lower loads expressed in Figure 7.

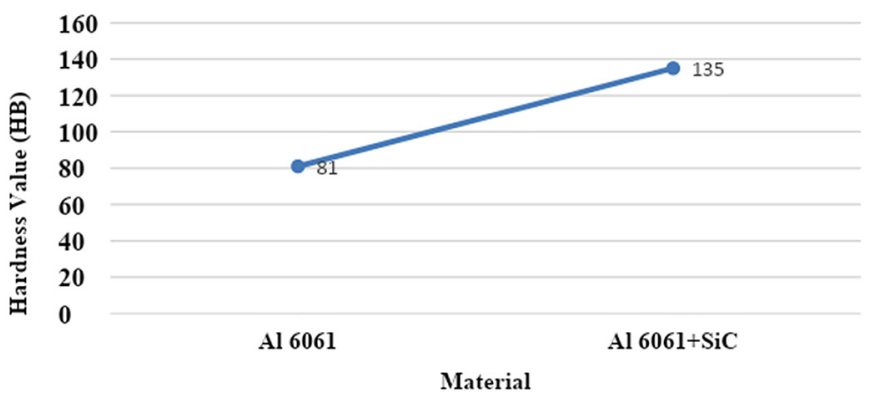

Fig. 4. Hardness of Al 6061 compared with Al6061 + SiC.

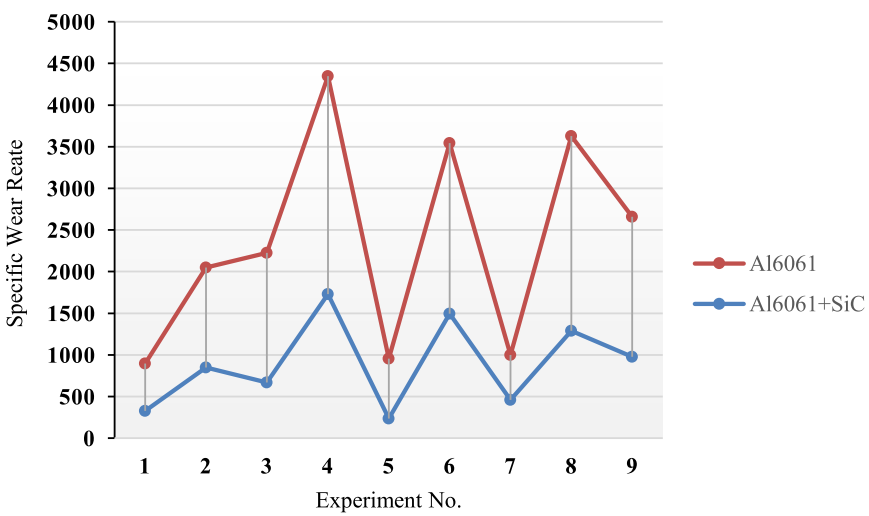

Fig. 5. Comparison of specific wear rate of Al6061 and $\mathrm{Al} 6061+\mathrm{SiC}$.

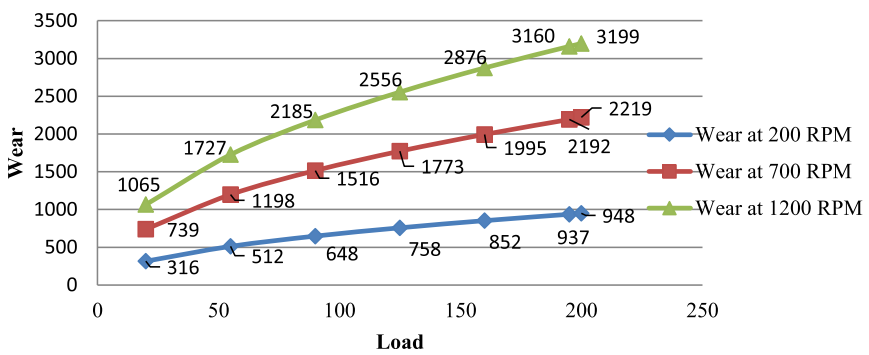

Fig. 6. Wear vs load at constant RPM for Al6061 alloy.

Similar results were obtained for $\mathrm{SiC}$ reinforced Al6061 composites as observed from Figures 8 and 9. Specific wear rate increases with increase in load. For 200 RPM it ranges between $112 \mu \mathrm{m}$ and $748 \mu \mathrm{m}$, for $700 \mathrm{RPM}$ it ranges between $228 \mu \mathrm{m}$ and $1521 \mu \mathrm{m}$ and for $1200 \mathrm{RPM}$ it ranges between $309 \mu \mathrm{m}$ and $2065 \mu \mathrm{m}$ with a load range of $20 \mathrm{~N}$ to 200 N. At higher RPM, the specific wear rate also increases, as presented in Figure 6. However the specific wear rate for the new composite is quite low as compared to Al6061 with same experimental conditions.

Even for experiments with constant loads for Al6061 + $\mathrm{SiC}$, the specific wear rate increases with an increase in RPM. For $20 \mathrm{~N}$ Load specific wear rate ranges between $112 \mu \mathrm{m}$ and $309 \mu \mathrm{m}$, for $110 \mathrm{~N}$ it ranges between $457 \mu \mathrm{m}$ and $1262 \mu \mathrm{m}$ and for $200 \mathrm{~N}$ it ranges between $748 \mu \mathrm{m}$ and $2065 \mu \mathrm{m}$. However the specific wear rate for $\mathrm{Al} 6061+\mathrm{SiC}$ is quite low as compared to Al6061 as indicated in Figure 9. 


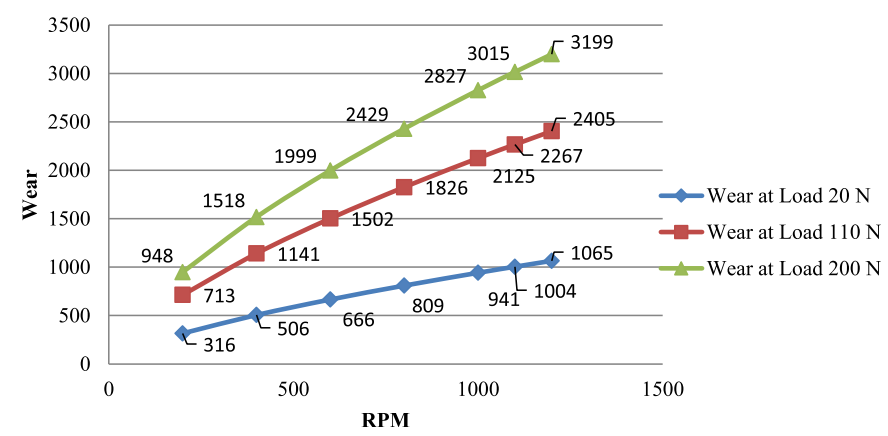

Fig. 7. Wear vs RPM at constant load for Al6061 alloy.

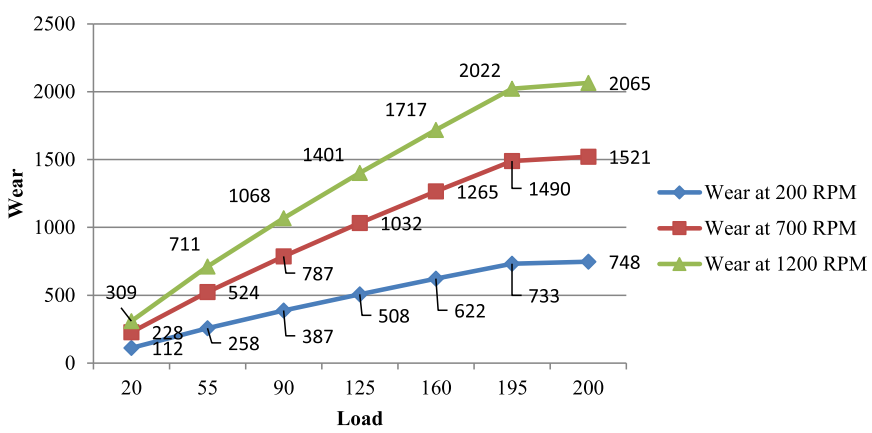

Fig. 8. Wear vs load at constant RPM for Al6061 $+\mathrm{SiC}$.

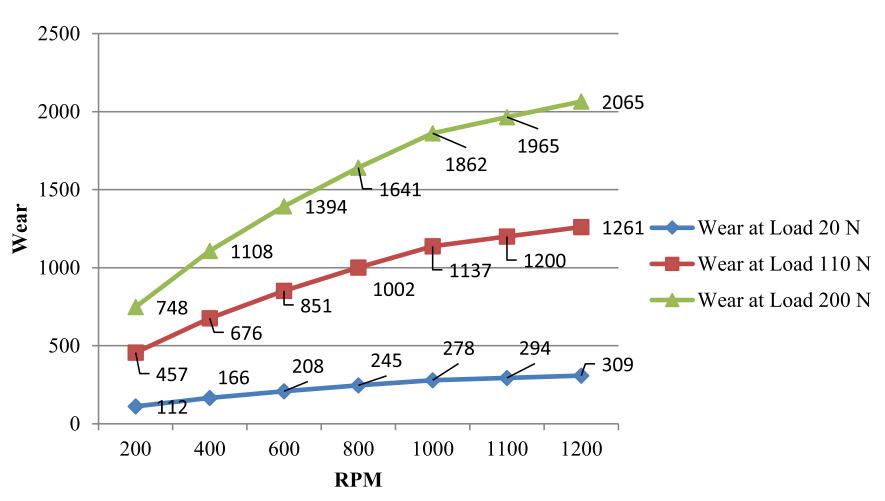

Fig. 9. Wear vs RPM at constant load for Al6061 $+\mathrm{SiC}$.

The influence of an increase in load on the specific wear rate is analysed for both Al6061 and Al6061 + SiC, the graph in Figure 10 shows an increase in specific wear rate with that of load. However specific wear rate for Al6061 + $\mathrm{SiC}$ is low as compared to Al6601. The influence of RPM on specific wear rate is analysed in Figure 11, which indicates that the specific wear rate increases with an increase in RPM in both materials, however for Al6061 the change is more with higher values.

The images of the wear track have been shown in Figures 12 and 13. It can be seen that there is adhesion in the case of Al6061 alloy. The Al6061 alloy being ductile in nature tends to adhere with the disc while testing the material for wear. Whereas in the case of the $\mathrm{SiC}$ reinforced MMC there was no adhesion.

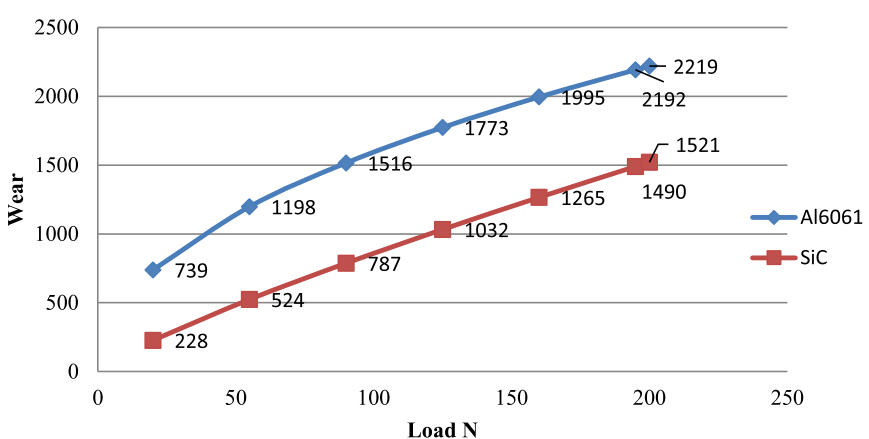

Fig. 10. Wear vs Load at 700 RPM.

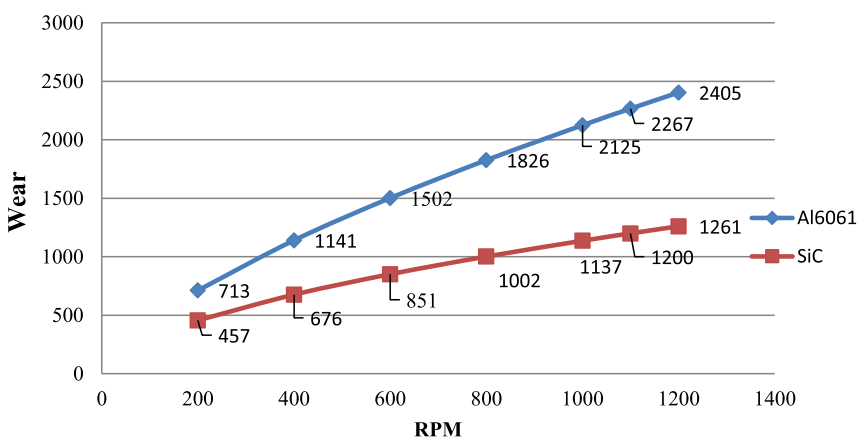

Fig. 11. Wear vs RPM at $110 \mathrm{~N}$ load.

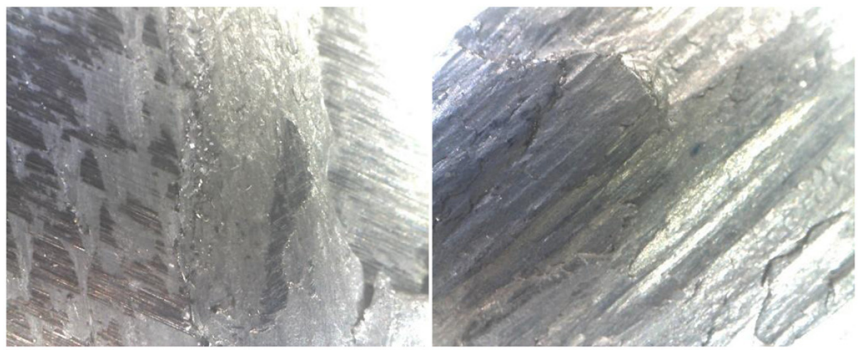

Fig. 12. Al6061 wear track.

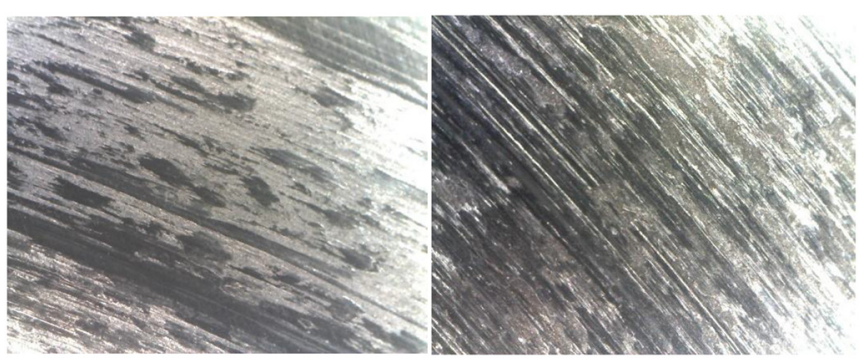

Fig. 13. Al6061 + SiC track.

\section{Conclusions}

The results of the newly developed composite of Al6061 and $5 \% \mathrm{SiC}$ has shown better wear characteristics as compared to Al6061. Also there is an appreciable enhancement in hardness value of the new composite. The knowledge base is enhanced with the insight that both RPM and load has a greater influence on the specific wear rate: 
- At constant load, as the RPM increases wear also increases.

- Similarly, at constant RPM, as the load increases wear increases.

- At constant RPM, with the increase in load the wear was found greater in the case of Al6061 than it was for Al6061-SiC.

- At constant load, with the increase in RPM the wear was also found greater in the case of Al6061 than Al6061-SiC.

It is therefore concluded that a reinforced SiC Metal Matrix Composite has better characteristics than an unreinforced Al6061 alloy.

\section{References}

1. R. Bauri, D. Yadav, Metal Matrix Composites by Friction Stir Processing, Butterworth-Heinemann, UK, 2018, pp. $1-15$

2. D.D.L. Chung, Metal-Matrix Composites Carbon Composites, Elsevier, 2017, pp. 532-562

3. M. Haghshenas, Metal-Matrix Composites, Reference Module in Materials Science and Materials Engineering, 2015, pp. $1-28$

4. N. Panwar, A. Chauhan, Fabrication methods of particulate reinforced aluminium metal matrix composite - a review, Mater. Today 5 (2018) 5933-5939

5. U.K. Annigeri, G.B. Veeresh Kumar, Method of stir casting of aluminum metal matrix composites: a review, Mater. Today 4 (2017) 1140-1146

6. M. Kumar Sahu, R. Kumar Sahu, Fabrication of Aluminum Matrix Composites by Stir Casting Technique and Stirring Process Parameters Optimization, Advanced Casting Technologies, edited by T.R. Vijayaram (2018), pp. 111-126. DOI: 10.5772/intechopen.73485

7. B. Chandra Kandpal, J. Kumar, H. Singh, Manufacturing and technological challenges in stir casting of metal matrix composites - a review, Mater. Today 5 (2018) 5-10

8. J. Hashim, L. Looney, M.S.J. Hashmi, Metal matrix composites: production by the stir casting method, J. Mater. Process. Technol. 92-93 (1999) 1-7

9. Y. Sumankant, C.S. Jawalkar, A. Singh Verma, N.M. Surie, Fabrication of aluminium metal matrix composites with particulate reinforcement: a review, Mater. Today 4 (2017) $2927-2936$
10. H. Kala, K.K.S. Mer, S. Kumar, A review on mechanical and tribological behaviours of stir cast aluminum matrix composites, Proc. Mater. Sci. 6 (2014) 1951-1960

11. A.T. Alpas, S. Bhattacharya, I.M. Hutchings, Wear of particulate metal matrix composites, in: Comprehensive Composite Materials II, Vol. 4, Elsevier Publications, 2018, https://doi.org/10.1016/B978-0-12-803581-8.09965-3

12. K. Vijaya Bhaskar, S. Sundarrajan, B. Subba Rao, K. Ravindra, Effect of reinforcement and wear parameters on dry sliding wear of aluminum composites - a review, Mater. Today 5 (2018) 5891-5900

13. M. Shukla, S.K. Dhakad, P. Agarwal, M.K. Pradhan, Characteristic behaviour of aluminium metal matrix composites: a review, Mater. Today 5 (2018) 5830-5836

14. A. Prasad Reddy, P. Vamsi Krishna, R. Narasimha Rao, N. V. Murthy, Silicon carbide reinforced aluminium metal matrix nano composites - a review, Mater. Today 4 (2017) 3959-3971

15. D. Das, P. Chandra Mishra, A. Kumar Chaubey, C. Samal, Characterization of the developed aluminium matrix composites - an experimental analysis, Mater. Today 5 (2018) 3243-3249

16. V. Balaji, N. Sateesh, M. Manzoor Hussain, Manufacture of aluminium metal matrix composite (Al7075-Sic) by stir casting technique, Mater. Today 2 (2015) 3403-3408

17. K. Kumar Singh, S. Singha, A. Kumar Shrivastava, Comparison of wear and friction behaviour of aluminum matrix alloy (Al 7075) and silicon carbide based aluminum metal matrix composite under dry condition at different sliding distance, Mater. Today 4 (2017) 8960-8970

18. G.B. Veeresh Kumar, C.S.P. Rao, N. Selvaraj, Studies on mechanical and dry sliding wear of Al6061-SiC composites, Composites Part B 43 (2012) 1185-1191

19. Md. Habibur Rahman, H.M. Mamun, Al Rashed, Characterization of silicon carbide reinforced aluminum matrix composites, Proc. Eng. 90 (2014) 103-109

20. A. Vedrtnam, A. Kumar, Fabrication and wear characterization of silicon carbide and copper reinforced aluminium matrix composite, Mater. Discov. 9 (2017) 16-22

21. K. Umanath, S.T. Selvamani, K. Palani Kumar, R. Sabarikreeshwaran, Dry sliding wear behaviour of AA6061-T6 reinforced $\mathrm{SiC}$ and $\mathrm{Al}_{2} \mathrm{O}_{3}$ particulate hybrid composites, Proc. Eng. 97 (2014) 694-702

22. K. Umanath, K. Palanikumar, S.T. Selvamani, Analysis of dry sliding wear behaviour of $\mathrm{Al} 6061 / \mathrm{Sic} / \mathrm{Al}_{2} \mathrm{O}_{3}$ hybrid metal matrix composites, Composites Part B 53 (2013) $159-168$

Cite this article as: Avinash Bhat, Ganesh Kakandikar, Manufacture of silicon carbide reinforced aluminium 6061 metal matrix composites for enhanced sliding wear properties, Manufacturing Rev. 6, 24 (2019) 